\title{
EXPERIENCE WITH DOLUTEGRAVIR IN HIV PATIENTS AT A PUBLIC SECTOR HOSPITAL IN KARACHI, PAKISTAN
}

\author{
Farzana Batool, Sohaima Manzoor, Azizullah Khan Dhiloo*, Humera Muhammad Ismail, Shah Muhammad Shaikh**, Shehla Baqai \\ Shaheed Mohtarma Benazir Bhutto Institute of Trauma \& Civil Hospital, Karachi Pakistan, *Dow University of Health Sciences, Karachi Pakistan, \\ ${ }^{* *}$ Civil Hospital, Karachi Pakistan
}

\begin{abstract}
Objective: To study the tolerability and efficacy of dolutegravir in naïve and experienced patients, their management and outcome.

Study Design: Cross sectional study.

Place and Duration of Study: Ruth KM Pfau Civil Hospital, Karachi Pakistan, from Apr 2018 to Apr 2020.

Methodology: In this study all treatment-naïve and experienced HIV infected patients were included and started on integrase strand-transfer inhibitor dolutegravir (DTG) containing fixed dose combination at Sindh AIDS Control Program (SACP) was conducted. We documented virological suppression, defined as a viral load of $<1000 \mathrm{copies} / \mathrm{ml}$, immunological and clinical outcomes.

Results: Eighty-two patients, of whom 53 (64.6\%) were Antiretroviral Therapy naïve and 29 (35.4\%) experienced, were started on DTG. Fifty-six $(68.3 \%)$ were males. The median age was $31.6 \pm 9$. Of 82,61 returned for their first follow-up visit for assessment and viral load determination. Of 61, adverse effects to DTG were reported in 12 (19.6\%), including 9 with pruritis. Of 35 naive patients, 30 achieved virological suppression by $3.3 \pm 0.7$ months and 1 at 8 months. All 26 experienced patients achieved virological suppression by $4.5 \pm 0.9$ months. Overall, of 61 patients, 57 (93.4\%) achieved virological suppression, of whom 1 had immunelogical failure and none had clinical failure after 6 months of DTG. Three (3.6\%) patients died within the first two months of initiating DTG.

Conclusion: Dolutegravir has good tolerability, with virological suppression achieved in the majority, including in highly ARV experienced patients.
\end{abstract}

Keywords: Antiretroviral therapy, Dolutegravir, Efficacy, HIV, Integrase Inhibitor, Outcome, Pakistan, Tolerability.

How to Cite This Article: Batool F, Manzoor S, Dhiloo AU, Ismail HM, Shaikh SM, Baqai S. Experience with Dolutegravir in HIV Patients at A Public Sector Hospital in Karachi, Pakistan. Pak Armed Forces Med J 2021; 71(5): 1661-1665. doi: https://doi.org/10.51253/pafmj.v71i5.6288

\footnotetext{
This is an Open Access article distributed under the terms of the Creative Commons Attribution License (https://creativecommons.org/licenses/by-nc/4.0/), which permits unrestricted use, distribution, and reproduction in any medium, provided the original work is properly cited.
}

\section{INTRODUCTION}

According to $\mathrm{WHO}$, Pakistan has a prevalence of HIV of $<1 \%$ with an estimated 150,000 cases and the highest incidence of HIV in the region with 21,000 new cases registered annually. ${ }^{1}$ The Sindh AIDS Control Program (SACP) introduced the integrase strandtransfer inhibitor dolutegravir (DTG) with lamivudine (3TC) and tenofovir fumurate (TDF) in fixed dose combination (DLT) in April 2018. According to WHO, the lower income countries with pre-treatment resistance to EFV or neviraprine at or above $10 \%$ should revise their first line regimen. DTG is now the preferred first line regimen in adults. ${ }^{2}$ These guidelines were adopted by our National Guidelines for the prevention and treatment of HIV. ${ }^{3}$

Cruciani and Parisi in 2019 in a meta-analysis of 7 randomized clinical trials in naïve patients demonstrated that dolutegravir containing antiretroviral therapy

Correspondence: Dr Farzana Batool, Fellow Infectious Disease, SMBBIT \& CH, Karachi Pakistan

Received: 12 Feb 2021; revision received: 15 Mar 2021; accepted: 16 Mar 2021
(ART) have an increased likelihood of achieving viral suppression. ${ }^{4}$ DTG is also known to have a high genetic barrier to resistance. ${ }^{5,6}$

Our aim was to study the tolerability and efficacy of dolutegravir in naïve and experienced patients, their management and outcome. There is no such data from Pakistan, to our knowledge. We also wanted to assess compliance by SACP with National HIV Guidelines in the management of patients started on a DTG containing regimen with the objective of improving patient care and outcomes, and ensuring that this newly introduced antiretroviral drug is appropriately utilized.

\section{METHODOLOGY}

We conducted a cross sectional, descriptive study at the SACP centre after approval from Ethical Review Committee (ERC\#000002/SMBBIT) and permission from Manager of SACP, from Apr 2018 to Apr 2020.

Inclusion Criteria: All the treatment-naïve and experienced HIV infected patients registered at the SACP and started on a DTG containing regimen. 
Exclusion Criteria: The pregnant women and $\leq 12$ years of age.

Based on a previous estimate of HIV viral load suppression found in (63.9\%) 8 of patients on dolutegravir with margin of error $11 \%$ and $95 \%$ confidence level, a sample size of 74 with allowance of attrition rate of $10 \%$, a total of 82 patients were required for this study, using OpenEpi calculator. The last date of patient enrollment was October 31, 2019, thus allowing for at least 6 months of follow-up and viral load determination.

Manual chart review was conducted for patient demographics, clinical, radiological and laboratory data. Baseline viral loads are not performed for naïve patients, but were available for experienced patients.

Patient drug compliance with ART was assessed based on the regularity of collection of ART and pill counting at the centre. In addition, clinical response was also gauged by the patient weight documented at each clinical visit.

As per National Guidelines, the first viral load after initiating ART should be performed at 3 months interval. If undetectable, the next VL is scheduled after 6 months whereas if detectable, VL must be repeated within 3 months for confirmation of failure. CD4 cell count determinations are recommended at baseline and then 6 monthly if less than 350 cells $/ \mathrm{mm}^{3}$.

We documented outcome in terms of clinical, immunological, virological suppression and failure as defined by our National Guidelines. ${ }^{3}$ Virological suppression was defined as a viral load of $<1000$ copies/ ml achieved by the first or second viral load determination on unchanged ART. 3 Virological failure was defined as a viral load $>1000$ copies/ml (based on two consecutive viral load measurements within a 3 month interval, with adherence support) after at least six months on unchanged ART. Three immunological failure was defined as a CD4 count persistently $<100$ cells/ul or decline below the base line level. 3 Clinical failure was defined as a new or recurrent clinical event indicating severe immunodeficiency after 6 months of effective treatment. ${ }^{3}$

Patient transfer to another HIV treatment facility, lost to follow up, or death were recorded.

Data was analyzed by using SPSS-24. Descriptive analysis was done; qualitative variables were presented as frequencies and percentages. Quantitative variables were either presented as mean and standard de- viation or were grouped into ranges for determination of frequency and percentages for each range.

\section{RESULTS}

At the end of the enrollment period, of 1183 patients receiving ARV at the SACP centre, $82(7 \%)$ patients were on a DTG containing regimen. Fifty six $(68.3 \%)$ were males, 24 were females $(29.3 \%)$ and 2 were transgender $(2.4 \%)$. The mean age was $31.6 \pm 9$ years. Of $82,76(93 \%)$ belonged to the province of Sindh. The route of HIV transmission was sexual in 42 $(51.2 \%)$, injecting drug use in $19(23.2 \%)$ and blood products in $17(20.7 \%)$ (Table-I).

Table-I: Baseline characteristics of HIV Infected patients started on dolutegravir $(\mathrm{n}=82)$.

\begin{tabular}{|c|c|}
\hline Baseline Parameter & n (\%) \\
\hline Age (years) & $31.6 \pm 9$ \\
\hline \multicolumn{2}{|l|}{ Gender } \\
\hline Male & $56(68.3)$ \\
\hline Female & $24(29.3)$ \\
\hline Transgender & $2(2.4)$ \\
\hline \multicolumn{2}{|l|}{ Occupation } \\
\hline Employed & $52(63.4)$ \\
\hline Unemployed & $11(13.4)$ \\
\hline House wife & $18(22)$ \\
\hline Student & $1(1.2)$ \\
\hline \multicolumn{2}{|l|}{ Education } \\
\hline Illiterate & $41(50)$ \\
\hline Primary & $23(28)$ \\
\hline Secondary & $9(11)$ \\
\hline College & $9(11)$ \\
\hline \multicolumn{2}{|l|}{ Risk Factor for HIV Exposure } \\
\hline Heterosexual contact (not spouse) & $25(30.4)$ \\
\hline HIV infected spouse & $15(18.2)$ \\
\hline Male homosexual contact & $2(2.4)$ \\
\hline Injecting drug use & $19(23.2)$ \\
\hline Blood products & $17(20.7)$ \\
\hline Unknown & $4(4.9)$ \\
\hline \multicolumn{2}{|l|}{ Co-Infections } \\
\hline Anti-HCV positive & $12(14.6)$ \\
\hline HBsAg positive & $17(20.7)$ \\
\hline Co-morbidities & $8(9.7)$ \\
\hline Thalassemia & $2(25.0)$ \\
\hline Chronic Kidney Disease & $1(12.5)$ \\
\hline Chronic Liver Disease & $3(37.5)$ \\
\hline Tuberculosis (active) & $2(25.0)$ \\
\hline \multicolumn{2}{|l|}{ Baseline CD4 (cells/mm³) } \\
\hline $\mathrm{n}($ Mean \pm SD) & $60(308 \pm 230.7)$ \\
\hline \multicolumn{2}{|l|}{ ARV Naive } \\
\hline $\mathrm{n}($ Mean $\pm \mathrm{SD})$ & $36(254.3 \pm 223.3)$ \\
\hline \multicolumn{2}{|l|}{ ARV Experienced } \\
\hline $\mathrm{n}($ Mean \pm SD) & $24(388.7 \pm 222)$ \\
\hline
\end{tabular}

Of 82,18 patients were lost to follow-up, transferred or died before their first scheduled follow-up visit. Of the remaining 64 patients, medications were 
collected regularly either by the patients themselves in $61(95.5 \%)$, or by their social mobilizers in $3(4.5 \%)$. Of $64,61(95.3 \%)$ returned for clinical assessment and first VL determination (VL1) whereas $3(4.6 \%)$ patients did not come for follow-up, averaging 8 months since DTG regimen initiated, though receiving ARVs. Therefore, tolerability, clinical and virological response could only be assessed in 61 patients. Of 61 patients, adverse effects attributed to DTG were seen in $12(19.7 \%)$ and included gastrointestinal in $1(1.6 \%)$, non- pruritic rash in $1(1.6 \%)$, depression in $1(1.6 \%)$ and pruritus in 9 $(14.7 \%)$. Of 82, $53(64.6 \%)$ were ARV naïve and 29 (35.4\%) were experienced.

In 53 ARV naïve patients, baseline viral loads had not been performed. After start of DTG regimen, VL1 could not be performed in those transferred (4), lost to follow (10) or died (1) due to CKD. Three patients had not returned for evaluation and testing, though receiving ARV. Therefore, VL1 was performed in $35(66 \%)$ out of 53 naïve patients at an average of $3.3 \pm 0.7$ months. Of $35,31(88.6 \%)$ had virological suppression. Of these, 30 achieved VL suppression at VL1 with sustained virological suppression demonstrated 6 months later in 2, and 1 achieved suppression at the second VL determination (VL2) at 8 months. Of 35, 4 (11.4\%) patients had detectable VL1. In 1, virological failure was confirmed. In 3 patients, virological failure for VL1 values of $2650 \mathrm{cps} / \mathrm{ml}, 5060 \mathrm{cps} / \mathrm{ml}$ and $85,000 \mathrm{cps} / \mathrm{ml}$ was not confirmed by a repeat VL. Of 53 patients, a baseline CD4 cell count was available in 36 with a mean of $254.3 \pm 223.3$. Of 36,4 patients had CD4 cell count determination after DTG initiation with an increase from a baseline mean of $295.5 \pm 181$ to $472.0 \pm 123$ at an average of 6 months since the start of DTG. Of 31 patients with virological suppression on DTG, none had clinical failure by 6 months. Their average weight at baseline was $48.5 \pm 9.8$ with an increase to $52.3 \pm 9.66$ at $3.3 \pm 0.7$ months.

In 29 ARV experienced patients, they were switched to DTG containing regimen due to side effects in $12(41.4 \%)$, suspected resistance in 11 (38\%), non-availability of RAL in $4(13.7 \%)$ and adoption of new guidelines in $2(6.9 \%)$. (Table-II) Baseline VL was available in all 29 , of whom $11(38 \%)$ were suspected of resistance to efavirenz, lamivudine and tenofovir (ELT) regimen due to high VL of a mean of $97122 \pm 86540 \mathrm{cps} / \mathrm{ml}$. Of 29, VL1 could not be performed in 3 patients as one was transferred and 2 had died due to HIV related causes, whereas 26 patients achieved virological suppression at an average of $4.5 \pm 0.9$ months. Of 29 , baseline
CD4 cell count was available in 24 at a mean of 388.7 \pm 222 . Repeat CD4 cell count was available in 5 virally suppressed patients with increase from a mean of 278 \pm 109 to $307.3 \pm 182$. Of 26 virally suppressed patients, none had clinical failure after 6 months of DTG. Their baseline weights averaged $55.2 \pm 11.8 \mathrm{~kg}$ before DTG with repeat weights after DTG in 19 patients showing gain from $57.7 \pm \mathrm{kg}$ to $61.3 \pm 12.4$ by $4.5 \pm 0.9$ months. Overall, in 82 naive and experienced patients on DTG, 61 patients had viral load determinations, of whom 57 (93.4\%) achieved virological suppression within the study period.

Assessment of the SACP centre's compliance with National HIV Guidelines in patient management revealed that DTG regimen was started promptly after registration in naïve patients. In experienced patients who reported significant side effects to prior regimen, or in case of non-availability of RAL, switch to DTG was also timely. However, in 11 patients with suspected resistance with confirmed virological failure, switch to DTG containing regimen was not initiated till an average of $3.3 \pm 2.9$ months later. Moreover, the ELT regimen was switched to DLT, thus substituting a single drug in a failing regimen. Of 82 patients, 2 with active tuberculosis were placed on treatment whereas 80 received isoniazid. Patients with CD4 cell count $<350$ cells $/ \mathrm{mm}^{3}$ or $<50$ cells $/ \mathrm{mm}^{3}$ were on PCP and MAC prophylaxis respectively. There was regular follow-up of patients who were collecting their ARV drugs themselves. Baseline CD4 determinations were not available in $22(26.8 \%)$ of 82 patients. Follow up CD4 determinations after start of DTG was performed in 9 of 27 $(33.3 \%)$ eligible patients, at an average of 6 months. VL1 was performed at an average of $3.9 \pm 1.0$ months in all eligible patients. However, VL2 was performed in only 3 of $25(12 \%)$ eligible patients. In 2 patients,

Table-II: Anti-Retroviral therapy in experienced patients $(\mathrm{n}=29)$.

\begin{tabular}{|c|c|}
\hline Variable & n (\%) \\
\hline \multicolumn{2}{|l|}{ Prior ART Regimen } \\
\hline NNRTI & $22(75.8)$ \\
\hline PI & $3(10.3)$ \\
\hline INSTI (Raltegravir) & $4(13.7)$ \\
\hline \multicolumn{2}{|l|}{ Main Reason for Switching ARV } \\
\hline Suspected resistance & $11(37.9)$ \\
\hline Side effects to efavirenz & $12(41.3)$ \\
\hline Rash & $2(16.7)$ \\
\hline Gynecomastia & $7(58.3)$ \\
\hline Depression & $3(25.0)$ \\
\hline Non-availability of raltegravir & $4(13.7)$ \\
\hline Adoption of new guidelines & $2(6.9)$ \\
\hline
\end{tabular}


virological failure was not confirmed within the recommended interval.

\section{DISCUSSION}

This is the first retrospective analysis of clinical experience with DTG in Pakistan, which was the second HIV integrase inhibitor to be made available nationally. Overall, $93.4 \%$ of our patients achieved viral suppression while $88 \%$ efficacy was reported in the single clinical trial. ${ }^{7}$ However in another efficacy study from Ireland, virological suppression was achieved in $63.9 \%$ of patients in 3 months. ${ }^{8}$ A study from India demonstrated $82.9 \%$ viral suppression after 6 months. ${ }^{9} \mathrm{~A}$ study from Hamburg Germany showed that at 3 months, viral suppression was recorded in $73 \%$ in treatment naïve and in $86 \%$ of treatment-experienced patients. A study from the UK demonstrated viral suppression as early as 1 month in $73 \%$ of naïve patients. ${ }^{10,11}$

Sustained virological suppression was demonstrated in $63.9 \%$ at 12 months in a study from Ireland 8 and in $92 \%$ in treatment naïve and $90 \%$ in treatment experienced at 12 months in a study from Germany. ${ }^{10}$ However, we were unable to demonstrate sustained suppression since virological monitoring was not optimally performed in our patient population.

Four patients in our study that were undetectable on raltegravir, did not show virological rebound after switch to dolutegravir. ${ }^{12}$

In our study, naïve patients had a mean CD4 cell count of 234 cells $/ \mathrm{mm}^{3}$ at registration at SACP whereas when compared to a 2010 study reported from the same center, baseline CD4 at registration was 130 cells $/ \mathrm{mm}^{3}$ suggesting that patients are now being detected earlier a decade later, which is encouraging. ${ }^{13}$

This study demonstrated a more robust immunological response to DTG in naïve as compared to experienced patients. This was also reported by Todd et al, whereby baseline CD4 cell count increased from 435 cells $/ \mathrm{mm}^{3}$ to 590 cells $/ \mathrm{mm}^{3}$ in naïve patients whereas it remained unchanged at 490 cells $/ \mathrm{mm}^{3}$ in experienced switch patients at week. ${ }^{12}$ In another study of DTG, in naïve patients baseline CD4 cell count increased from a mean of 225 cells $/ \mathrm{mm}$ to 336 cells $/ \mathrm{mm}$ after 3 month and to 463 cells/mm after 12 months, while in experienced increase was from a mean of 424 cells/ $\mathrm{mm}^{3}$ to 478 cells $/ \mathrm{mm}^{3}$ after 3 month and to 536 cells/ $\mathrm{mm}^{3}$ after 12 months. A meta-analysis reported a greater increase in CD4 cell count with DTG as compared to efavirenz, which was the first line ARV prior to DTG prescribed by our centre. ${ }^{10,11,14}$
We found patient compliance with collection of medications to be excellent, as was also seen in the earlier 2010 study of SACP. Overall, clinical response was good in both naïve and experienced patients in our study with no opportunistic infections documented beyond 3 months. We report early mortality of $3.6 \%$ within the first 2 months of starting DTG. When compared with mortality data reported from the 2010 study from the same centre, our mortality is much lower than the $23.3 \%$ HIV related deaths reported then. ${ }^{13}$ This is likely related to earlier detection of patients with HIV at present and higher efficacy of Integrase Strand Transfer Inhibitor (INSTI) containing ART.

We reported adverse effects attributed to DTG in $19.7 \%$, whereas in other studies adverse effects in $35 \%$, $39 \%$ and $42.2 \%$ of patients have been reported. $8,11,15$ Discontinuation rates due to neuropsychiatric effects were reported in $5.6 \%$ of patients by Hoffman et al, and in $6.9 \%$ by Cid-Silva et al, whereas only 1 patient reported depression after starting DTG which did not lead to discontinuation in this study. ${ }^{16,17}$

SACP centre demonstrated prompt initiation of ARV and maintained a steady supply of ARVs. However, SACP must ensure that baseline CD4 cell counts with subsequent monitoring is performed, which is essential for prophylaxis and its discontinuation. Follow-up of patients with close VL monitoring is essential for early detection of virological failure and prevention of drug resistance, in case of which switch to effective regimen must be prompt. Most crucially, substitution of a single drug in a failing regimen must never be allowed since the development of resistance is a major concern, and drug resistance testing is not widely available in resource poor settings such as ours. ${ }^{18}$

Our study has demonstrated excellent efficacy of DTG in both naïve and experienced patients, good tolerability and outcomes and therefore appears to be a better option for our patient population than an nonnucleoside reverse transcriptase inhibitors (NNRTI) based regimen. However, further studies will be required to determine superiority.

\section{LIMITATION OF STUDY}

Limitations of this study include a retrospective study design with missing information. It is a single center study with a small sample size. However, it has provided valuable information regarding the acceptability and outcome of a DTG containing regimen in our patient population. 


\section{Dolutegravir in HIV}

\section{CONCLUSION}

DTG is well tolerated by patients, with virological suppression being achieved in the majority of patients, including in highly ARV experienced patients.

Conflict of Interest: None.

\section{Authors' Contribution}

FB: Conception and frame work, SM: Drafting, AKD: Data analysis \& collection, HMI: Data collection, SMS: Drafting, SB: Critical reviw.

\section{REFERENCES}

1. HIV cases-Pakistan [Internet]. World Health Organization. 2020, [Internet] Available from:https://www.who.int/csr/don/03july-2019-HIV-cases-pakistan/en/[Accessed on October 3,2020].

2. World Health Organization.. Updated recommendations on firstline and second-line antiretroviral regimens and post-exposure prophylaxis and recommendations on early infant diagnosis of HIV: interim guidelines: supplement to the 2016 consolidated guidelines on the use of antiretroviral drugs for treating and preventing HIV infection, [Internet] Available from: https:/ / app s.who.int/iris/handle/10665/277395 [Accessed on Oct 10, 2020].

3. Consolidated Guidelines for the prevention and treatment of HIV and AIDS in Pakistan 2020 [Accessed on October 10, 2020], https:// phkh.nhsrc.pk/sites/default/files/2020-

10/National\%20Guidelines\%20for\%20Clinical\%20Management \%20of\%20HIV-AIDS\% 20UNAIDS\%202001.pdf

4. Cruciani M, Parisi SG. Dolutegravir based antiretroviral therapy compared to other combined antiretroviral regimens for the treatment of HIV-infected naive patients: A systematic review and meta-analysis. PLoS One 2019; 14(9); e0222229.

5. Kandel CE, Walmsley SL, Kandel CE, Walmsley SL. Dolutegravir-a review of the pharmacology, efficacy, and safety in the treatment of HIV. Drug Des Devel Ther 2015; 9(2): 3547-3555.

6. Rusconi S, Adorni F, Tau P, Borghi V, Pecorari M, Maserati R, et al. Dolutegravir (DTG)-containing regimens after receiving raltegravir (RAL) or elvitegravir (EVG): durability and virological response in a large Italian HIV drug resistance network (ARCA). J Clin Virol 2018; 105(1): 112-117.

7. Walmsley SL, Antela A, Clumeck N, Duiculescu D, Eberhard A. Dolutegravir plus abacavir-lamivudine for the treatment of HIV1 infection. N Engl J Med 2013; 369(19): 1807-18.

8. Waqas S, O'Connor M, Levey C, Mallon P, Sheehan G, Patel A, et al. Experience of dolutegravir in HIV-infected treatment-naive patients from a tertiary care University Hospital in Ireland. SAGE Open Med 2016; 4(2): 2050312116675813.
9. Kumarasamy N, Prabhu S, Chandrasekaran E, Poongulali S, Pradeep A, Chitra D, et al. Safety, Tolerability, and efficacy of generic dolutegravir-containing art regimens among south indian HIV-infected patients. Clin Infect Dis 2019; 68(6): 10481051.

10. Brehm TT, Franz M, Hüfner A, Hertling S, Schmiedel S, Degen $\mathrm{O}$, et al. Safety and efficacy of elvitegravir, dolutegravir, and raltegravir in a real-world cohort of treatment-naive and-experienced patients. Med (Baltimore) 2019; 98(32): e16721.

11. Todd SE, Rafferty P, Walker E, Hunter M, Dinsmore WW, Donnelly CM, et al. Early clinical experience of dolutegravir in an HIV cohort in a larger teaching hospital. Int J Std Aids 2017; 28(11): 1074-1081.

12. Sangaré MN, Baril JG, de Pokomandy A, Ferreira Guerra S, Carabali M, Laprise C, et al.Treatment Switch to Dolutegravir with 2 nucleoside reverse-transcriptase inhibitors (NRTI) in comparison to continuation with protease inhibitor/ritonavir among patients with human immunodeficiency virus at risk for prior NRTI resistance: a cohort analysis of real-world data. Open Forum Infect Dis 2020; 7(11): ofaa404.

13. Baqi S, Abro AG, Salahuddin N, Ashraf Memon M, Qamar Abbas S, Baig-Ansari N. Four years of experience with antiretroviral therapy in adult patients in Karachi, Sindh, Pakistan. Int Health 2012; 4(4): 260-267.

14. Patel DA, Snedecor SJ, Tang WY, Sudharshan L, Lim JW, Cuffe $\mathrm{R}$, et al. 48-week efficacy and safety of dolutegravir relative to commonly used third agents in treatment-naive HIV-1-infected patients: a systematic review and network meta-analysis. PLoS One 2014; 9(9): e105653.

15. Rodriguez-Gonzalez CG, Chamorro-de-Vega E, Ortega-Navarro C, Alonso R, Herranz-Alonso A, Sanjurjo-Saez M. Effectiveness, Safety, and Costs of Dolutegravir/Abacavir/Lamivudine SingleTablet Regimen in a Real-Life Cohort of HIV-1 Adult Infected Patients. Ann Pharmacot 2020; 54(7): 633-643.

16. Mondi A, Cozzi Lepri A, Tavelli A, Rusconi S, Vichi F, Ceccherini Silberstein $\mathrm{F}$, et al. Effectiveness of dolutegravir based regimens as either first line or switch antiretroviral therapy: data from the Icona cohort. J Int AIDS Soc 2019; 22(1): e25227.

17. Cid-Silva $\mathrm{P}$, Llibre JM, Fernández Bargiela N, Margusino Framiñán L, Balboa Barreiro V, Pernas Souto B, et al. Clinical experience with the integrase inhibitors dolutegravir and elvitegravir in HIV infected patients: efficacy, safety and tolerance. Basic Clin Pharmacol Toxicol 2017; 121(5): 442-426.

18. Siedner MJ, Moorhouse MA, Simmons B, de Oliveira T, Lessells $\mathrm{R}$, Giandhari J, et al. Venter WD. Reduced efficacy of HIV-1 integrase inhibitors in patients with drug resistance mutations in reverse transcriptase. Nat Commun 2020; 11(1): 5922-5929. 